University of Nebraska - Lincoln

DigitalCommons@University of Nebraska - Lincoln

1998

\title{
Assessment of Urban Heat Islands: A Multi-Sensor Perspective for the Dallas-Ft. Worth, USA Region
}

Kevin P. Gallo

National Climatic Data Center, Kevin.P.Gallo@noaa.gov

Timothy W. Owen

NOAA/NESDIS/National Climatic Data Center

Follow this and additional works at: https://digitalcommons.unl.edu/natrespapers

Part of the Natural Resources and Conservation Commons

Gallo, Kevin P. and Owen, Timothy W., "Assessment of Urban Heat Islands: A Multi-Sensor Perspective for the Dallas-Ft. Worth, USA Region" (1998). Papers in Natural Resources. 186.

https://digitalcommons.unl.edu/natrespapers/186

This Article is brought to you for free and open access by the Natural Resources, School of at DigitalCommons@University of Nebraska - Lincoln. It has been accepted for inclusion in Papers in Natural Resources by an authorized administrator of DigitalCommons@University of Nebraska - Lincoln. 


\title{
Assessment of Urban Heat Islands: A Multi-Sensor Perspective for the Dallas-Ft. Worth, USA Region
}

\author{
Kevin P. Gallo \\ NOAA/NESDIS/Office of Research and Applications, \\ 5200 Auth Road Camp Springs, MD 20746, U.S.A.

\section{Timothy W. Owen} \\ NOAA/NESDIS/National Climatic Data Center, \\ Asheville, NC, 28801, U.S.A.
}

\begin{abstract}
Data acquired during the early to mid-1990s by several satellite-sensor systems were combined in an assessment of the urban heat-island effect for the Dallas-Fort Worth, TX region of the United States. Normalized difference vegetation index and radiant surface temperature were computed from NOAA-AVHRR data. Two measures of the anthropogenic light emitted by urban-related surface features were available from the DMSP-OLS. Landsat MSS data were used to provide estimates of the predominant land cover within the grid cells associated with the NOAAAVHRR and DMSP-OLS data. The multi-sensor analysis of the environment associated with seven climate observation stations in the Dallas-Ft. Worth region provided a methodology for characterization of the stations as "urban" or "rural." Three of the seven stations examined were identified through this analyis as "urban." The information provided by a single sensor, while valuable, was clearly enhanced by the use of the multiple sensors included in this study.
\end{abstract}

\section{Introduction}

Climatologists have long been interested in the differences in observed ambient air temperature between cities and their surrounding rural regions, which have been well documented (e.g., Landsberg, 1981; Kukla et al. 1986; Karl et al. 1988; Changnon 1992; Gallo et al. 1993a; Gallo et al. 1996). Urban climate studies have traditionally focused on the magnitude of such differences, which collectively describe the Urban Heat Island (UHI) effect. This effect is not restricted to large metropolitan areas. In fact, it has been detected in cities with populations of less than 10,000 (Karl et al., 1988).

Whether one considers a sprawling metropolis or a small town, the UHI effect is linked to differences in the composition of the earth's surface between rural and urban locations. Urban development usually results in a dramatic alteration at the surface, as natural vegetation is removed and replaced by reduced evaporating, non-transpiring surfaces (e.g., asphalt, stone, metal, concrete). Under such alteration, the partitioning of incoming solar radiation into fluxes of sensible and latent heat is skewed in favor of increased sensible heat flux as evapotranspiring surfaces are reduced. From thermal infrared measurements $(10.5-11.5 \mu \mathrm{m})$ acquired by the Advanced Very High Resolution Radiometer (AVHRR) aboard the NOAA series of polar orbiting satellites? Roth et al. (1989) derived surface temperature data and assessed its spatial distribution across several cities along the west coast of North America. Elevated daytime surface temperatures were highly correlated to the patterns of land cover related to urban land use (i.e., higher surface temperatures corresponded to industrial areas while considerably cooler surface temperatures corresponded to well-vegetated residential areas).

In the absence of solar illumination of the surface at night, however, Roth et al. (1989) found that the relationship between surface temperature and urban land use was illdefined. Yet this is the time when the UHI effect is greatest, which is reflected by the finding by Karl et al. (1988) that urbanization within the United States exerts its greatest influence on minimum (compared to maximum or mean) temperature (which is mainly a nighttime phenomenon). Roth et al. (1989) attributes this apparent contradiction to the emission of thermal infrared radiation from the sides of buildings (rather than roofs) at night.

Although thermal infrared satellite measurements cannot directly measure the UHI effect, they can be coupled with satellite-derived measurements of vegetation density to substantially describe the contributing factors to the UHI effect. The role of vegetation in reducing the amount of heat stored in the soil and surface structures due to transpiration, in contrast to relatively unvegetated urban areas, has been cited as a significant contributor to the UHI effect (Carlson et al., 1981; Goward, 1981). Vegetation indices computed 
from remotely sensed data have been demonstrated as useful estimators of the amount of leaf area and related variables associated with agricultural crops (Gallo and Daughtry, 1987), as well as forests (Nemani and Running, 1989).

Gallo et al. (1993a, 1993b) compared vegetation indices and radiant surface temperature acquired by the AVHRR with minimum air temperatures observed for urban and rural locations The satellite-derived vegetation index data of a monthly composite were linearly related to the difference in observed urban and rural minimum temperatures, explaining $37 \%$ of its variation (versus $15 \%$ using radiant surface temperature). Thus, during the growing season and in wellvegetated regions, a vegetation index is a useful parameter for assessing the UHI effect.

In addition to land cover parameters derived from the AVHRR, Gallo et al. (1995) found that "city lights" data

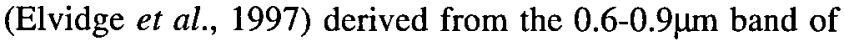
the Operational Linescan System (OLS) of the U.S. Air Force Defense Meteorological Satellite Program (DMSP) appeared useful in distinguishing between urban and rural locations. The "city lights" data set offers the prospect of periodic and objective assessments of urban expansion at a continental-scale.

Given the relationship between the UHI effect, urban surface temperatures and the texture of land cover influenced by urban land use, this paper outlines a multi-sensor approach to assess the climatic implications of urbanization at the regional-scale (i.e., tens of kilometers). The AVHRR instrument provides data that can be used to derive both surface temperature and a measure of vegetation at the surface resolution of $1 \mathrm{~km}^{2}$. Identification of urban land cover is attainable through Landsat MSS at a resolution of $80 \mathrm{~m}^{2}$. In addition, the DMSP-OLS provides information on nighttime anthropogenic sources of light at a resolution of $2.7 \mathrm{~km}^{2}$ that can be used as an additional tool in verifying the distinction between urban and rural locations.

\section{Objectives}

The general objective of the paper is to provide an overview of the application of data and products available from the AVHRR, Landsat MSS and DMSP-OLS sensors to studies of urban climate. A more specific objective is to demonstrate how the data from these sensors can be used to assess whether a given meteorological station can be characterized as "urban" or "rural." An objective method for determining whether a station is urban or rural would be beneficial for the assessment of global climate change, as the influence of urban stations could be extracted from future analyses of temperature trends.

\section{Data and Methodology}

\section{Data Analysis}

The Dallas-Fort Worth (DFW), Texas, USA, metropolitan area was selected for this analysis. The population associated with this metropolitan region has increased from 2.3 million in 1970 to an estimated 4.4 million in 1995 (U.S. Bureau of the Census, 1997). AVHRR and DMSP-OLS data were sampled for 7 climatological stations (Table 1) included in the DFW region. These stations are part of a larger network of stations throughout the USA being utilized to examine the heat-island effect (Gallo et al., 1993a). The reported AVHRR and DMSP-OLS values are the mean values for $3 X 3 \mathrm{~km}^{2}$ "windows" centered on the location of the climatological stations, unless otherwise noted.

Table 1 Dallas-Ft. Worth Climatological Stations included in this study, with mean values of the AVHRR and DMSP-OLS data extracted for the stations.

\begin{tabular}{lcccc}
\hline ID Name & NDVI & Tsfc & OLS-pct & OLS-cal \\
279 Corsicana & 0.35 & 45.78 & 81.4 & 13.1 \\
280 Bardwell Dam & 0.39 & 44.14 & 0.0 & 0.0 \\
281 Waxahachie & 0.32 & 45.92 & 81.9 & 14.6 \\
282 Ferris & 0.42 & 45.31 & 4.7 & 1.6 \\
283 Kaufman 3 SE & 0.35 & 49.84 & 0.9 & 1.3 \\
284 Wills Point & 0.32 & 49.92 & 22.6 & 2.3 \\
285 Dallas FAA AP & 0.26 & 47.89 & 99.2 & 90.6 \\
\hline
\end{tabular}
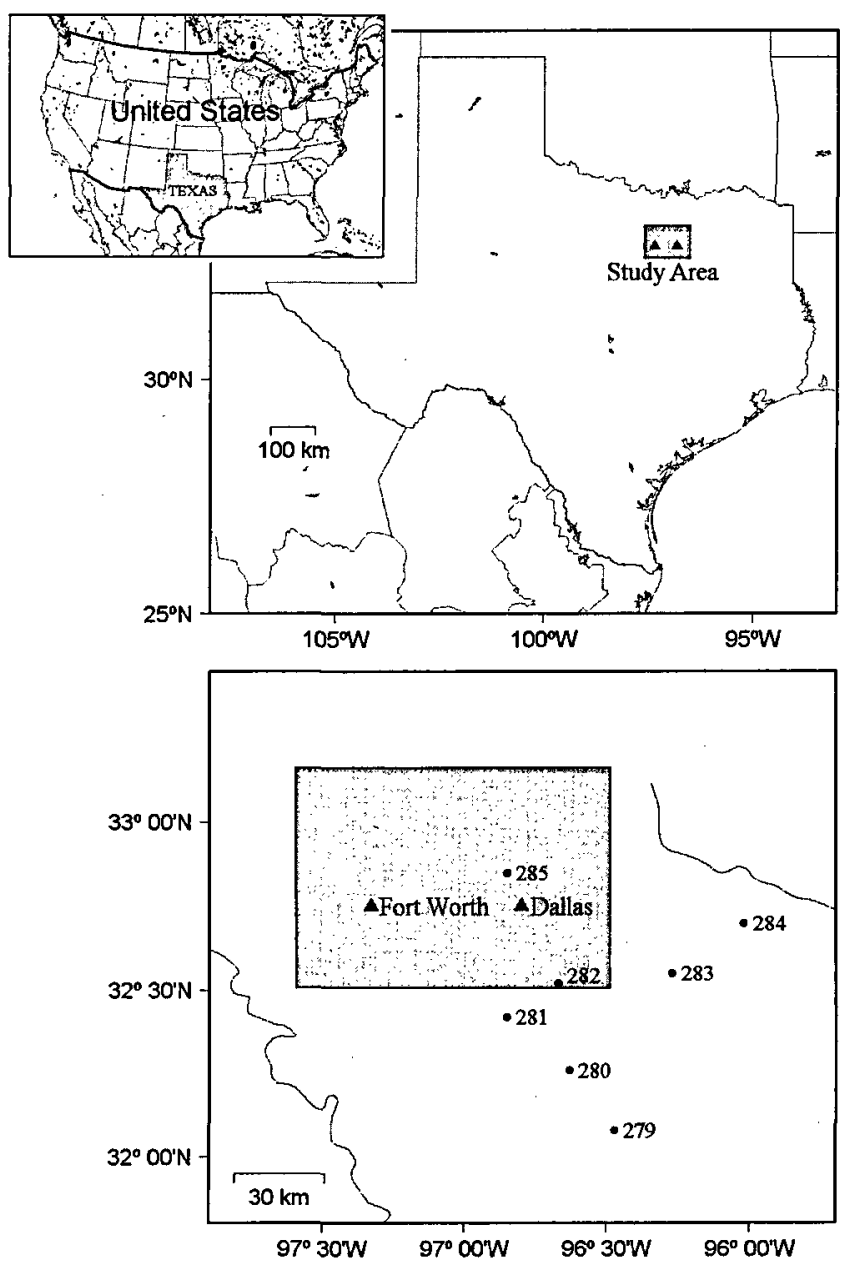

Figure 1 Map location of study region within Texas, and climate station locations. Shaded region of study area represents extent of Landsat MSS scene. 


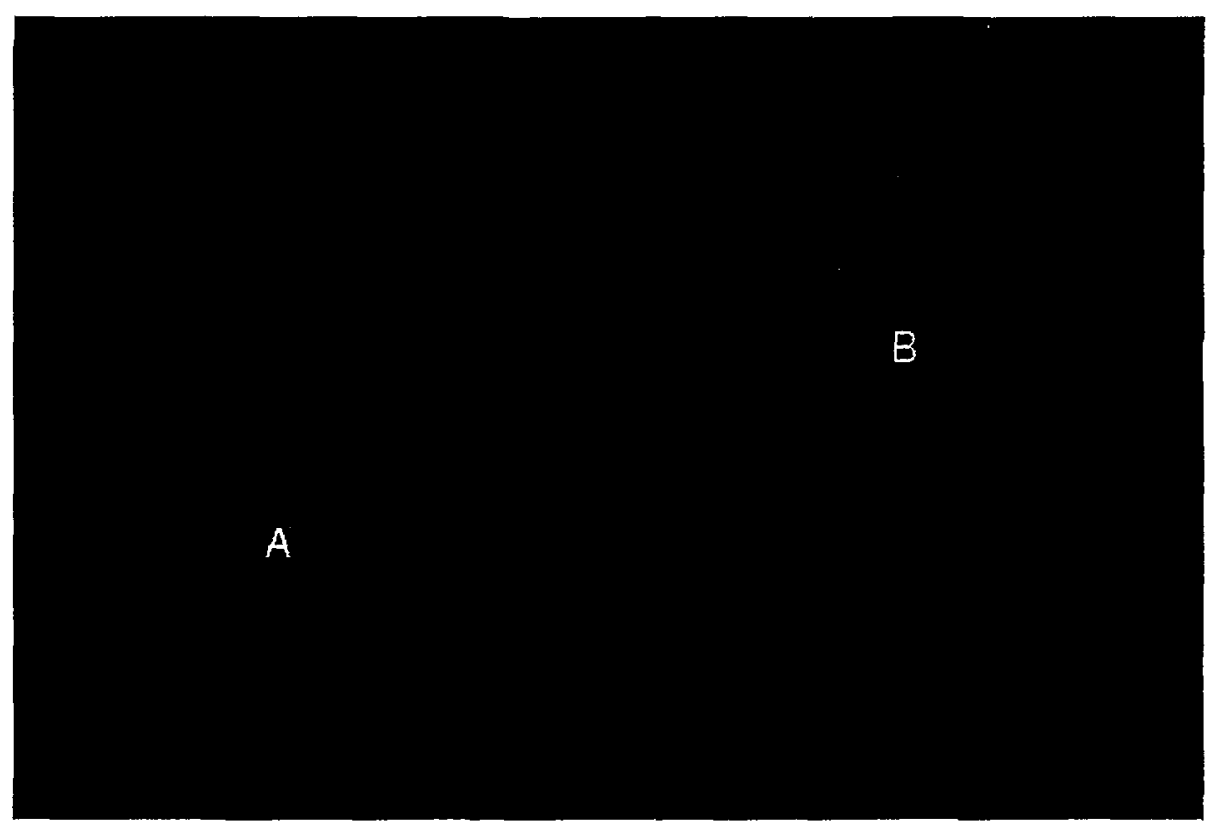

Figure 2 Landsat MSS-based land cover classification for the Dallas (indicated by "B") and Ft. Worth ("A"), TX region. Urban land cover is indicated by red, water by blue, and forested by green.

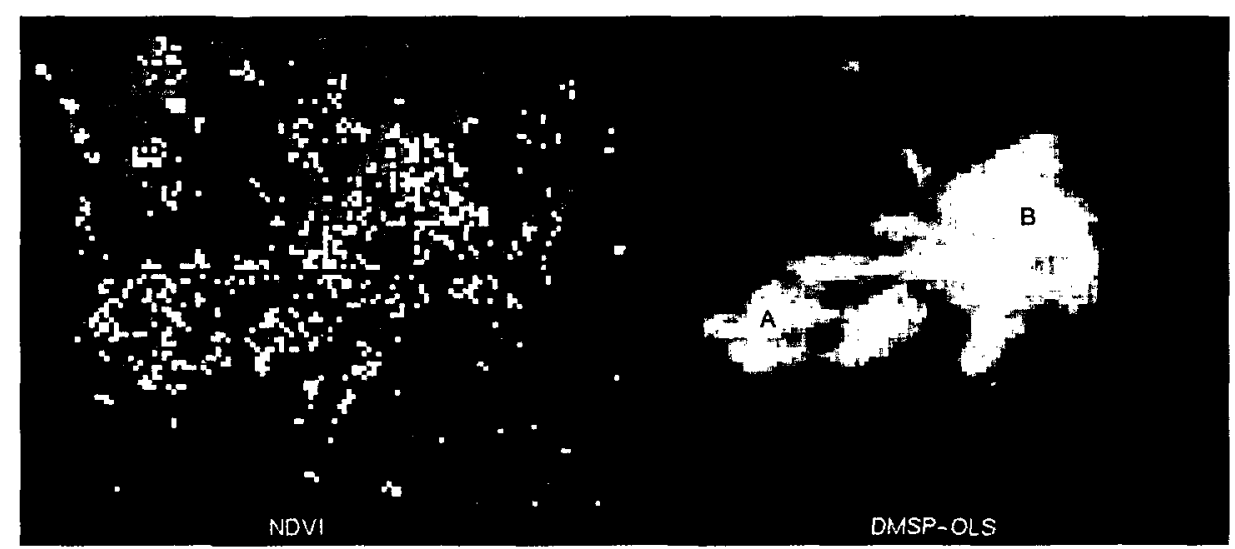

Figure 3 NDVI and DMSP-OLS (calibrated) data for the Dallas (indicated by "B" in DMSP-OLS figure) and Ft. Worth ("A"), TX region. Low NDVI values are indicated by blue/gray/yellow tones and greater NDVI values are indicated by green tones. OLS-cal values are indicated by brightness of pixels, with brighter pixels representative of greater OLS-cal values. Approximate location of a transect selected for additional analysis (Figure 4) is displayed as black line in NDVI image.

\section{AVHRR-Derived Vegetation Index}

Normalized Difference Vegetation Index (NDVI) values, computed (equation 1$)$ from the visible $(\mathrm{C} 1 ; 0.58-0.68 \mu \mathrm{m})$ and near-infrared $(\mathrm{C} 2 ; 0.72-1.1 \mu \mathrm{m})$ data acquired by the AVHRR as

$$
\mathrm{NDVI}=(\mathrm{C} 2-\mathrm{C} 1) /(\mathrm{C} 2+\mathrm{C} 1)
$$

were obtained from two products for use in this analysis. The NDVI, like most other vegetation indices, exploits the difference in the reflectance of vegetation in the near-infrared wavelengths compared to visible wavelengths. Multiple scenes for a given time period (typically 10-day, 14day or monthly) are composited by retaining, on a pixel-by-pixel basis, the maximum observed value of NDVI during the interval. Composited NDVI images minimize the probability that pixels with cloud or haze contamination (which result in lower NDVI values) will remain in the image.

Fourteen-day composited NDVI and individual channel AVHRR data are readily available for the Conterminous USA at the $1-\mathrm{km}$ resolution in a Lambert Azimuthal Equal Area (LAEA) projection. NDVI values were extracted from a CD-ROM product (USGS, 1991) for two 14-day composite 
intervals of 1991. The data of the two 14-day composites were then further composited over a 28-day interval (5 July through 1 August 1991).

\section{AVHRR-Derived Radiant Surface Temperature}

Radiant surface temperature (Tsfc) can be approximated from calibrated thermal IR data of channels 4 (T4; 10.3 $11.3 \mu \mathrm{m})$ and $5(\mathrm{~T} 5 ; 11.5-12.5 \mu \mathrm{m})$ of the AVHRR sensor for a surface emissivity of 1.0 as suggested by Price (1990) as

$$
\mathrm{Tsfc}=\mathrm{T} 4+3.3(\mathrm{~T} 4-\mathrm{T} 5)
$$

Oke (1987) cites emissivity values for vegetation (agricultural crops; deciduous and coniferous forests) that range from 0.90 to 0.97 , while values for urban surfaces (concrete, asphalt, and stone) range from 0.71 to 0.95 . Surface emissivity differences between the examined urban and rural regions were not available and thus not included in the estimate of Tsfc. The T4 and T5 data associated with the NDVI values composited over the 5 July through August 1991 interval were used to compute Tsfc. The Tsfe of this interval was selected for analysis to permit direct examination of the relationship between Tsfe and NDVI at the climate stations.

\section{DMSP-OLS-Derived "City Lights" Data}

The DMSP-OLS data have historically been used to monitor the global distribution of clouds and cloud top temperatures. However, the data acquired in the visible/ near-infrared band $(0.6-0.9 \mu \mathrm{m})$ at night under cloud-free conditions can be used to identify light emitted at the surface of the earth. Gallo et al. (1995) demonstrated that this data might be useful for identification of urban and rural locations as it primarily identifies the light associated with urban locales (e.g., "city lights"). However, caution must be used when these data are used for identification of urban areas as, on any single night, the burning of forests (e.g., burning biomass) and fossil fuels could be misinterpreted to represent the location of an urban areas.

Two DMSP-OLS data sets were used in this analysis. The first DMSP-OLS data product was based on a composite of 231 orbits that were used to identify stable (e.g., urban areas) from nonstable (e.g., burning biomass) light sources. The orbital data were mapped to a $1-\mathrm{km}$ (Goodes Homolosine) projection. The DMSP-OLS data were provided by the National Geophysical Data Center and are based on data acquired during 1994 and 1995. The values of the OLS data for this data set, designated as OLS-pct, were computed as the ratio of the number of scenes in which light was observed at a given pixel to the number of cloud free scenes for that pixel (Elvidge et al., 1997)

The second DMSP-OLS data product was based on digitally calibrated (to units of Watts $/ \mathrm{cm}^{2} / \mathrm{sr} / \mu \mathrm{m}$ ) OLS data acquired over a portion of North America from 16-23 March 1996. The OLS calibrated product, designated "OLS-cal" and OLS-pct data were remapped from the Interrupted Goode Homolosine projection to the LAEA projection of the
AVHRR data.

\section{Landsat MSS LULC Classified Data}

For purposes of validation of the above parameters, it is necessary to have an objective characterization of urbanized area in order to facilitate spatial correlation. Landsat MSS images, prepared for a North American Landscape Characterization project (USGS, 1997a) were obtained for the DFW region. The MSS data were also remapped, from a UTM projection to the LAEA projection of the AVHRR data. Additionally, the MSS data were resampled to a resolution of $50 \mathrm{~m}^{2}$ to precisely fall within the larger $1 \mathrm{~km}^{2}$ grid cell resolution of the AVHRR and DMSP-OLS data (i.e., $400 \mathrm{MSS} 50 \mathrm{~m}^{2}$ grid cells per $1 \mathrm{~km}^{2}$ AVHRR or DMSP-OLS grid cell). While the MSS scene included most of the Dallas-Ft. Worth metropolitan region (Figure 1), only two of the climate stations were located within the borders of the MSS scene.

The classification scheme of Anderson et al. (1976) was applied to a Landsat MSS image of the Dallas-Ft. Worth region for a MSS scene acquired on 8 October 1992. The resultant classes derived included agricultural, urban, water, forested, rangeland, and bare soil, as well as an unclassified class.

The derived classes were obtained using the Land Analysis System image processing software package (LAS; USGS, 1997b). The procedure for image classification began by first inputting four channels of the resampled Landsat MSS data $(0.5-0.6 ; 0.6-0.7 ; 0.7-0.8$; and $0.8-1.1 \mu \mathrm{m})$ into the CLUSTER unsupervised classification procedure. Twentyfour spectrally separate clusters were subsequently output with accompanying covariance matrices. Heterogeneous clusters with large offdiagonal covariance values were merged into the unclassified class. The other clusters were merged into the six Anderson Level I classes using ground truthing guidance from the USGS 200 meter Anderson Level II data set (USGS, 1990).

Using the Anderson classified Landsat MSS data, subpixel percentages of each class were aggregated to the same $1 \mathrm{~km}^{2}$ grid used in deriving AVHRR and DMSP-OLS parameters. The aggregation for each $1 \mathrm{~km}^{2}$ grid cell was determined as:

Class percentage $=100\left(\right.$ Number of MSS $50 \mathrm{~m}^{2}$ class pixels/400).

Classes were defined as predominant within a $1 \mathrm{~km}^{2}$ grid cell when they were at least $50 \%$ present in the grid cell.

\section{Results}

The MSS classified image is displayed in Figure 2 with the urban (red), water (blue) and forested (green) classes identified. The rangeland, agricultural, bare soil, and unclassified classes are displayed as black. The urban identified regions of the MSS image visually match those regions in the NDVI and OLS-cal images of the DFW region (Figure 3) with lower NDVl values and greater DMSP-OLS 
values, while the rural areas display greater NDVI values and lower DMSP-OLS values.

A $110 \mathrm{~km}$ transect that intersected the DFW region was examined in greater detail (Figure 4). The transect is $3 \mathrm{~km}$ in width and lies west to east (left to right in Figure 3) through the DFW region. The transect passes through Fort Worth approximately between the 30 to $50 \mathrm{~km}$ interval on the transect, and Dallas between the 60 to $100 \mathrm{~km}$ interval. The dips in the NDVI data at $72 \mathrm{~km}$ and again between 101 and $103 \mathrm{~km}$ along the transect are associated with a river and reservoir, respectively. The dip in the OLS data at the 80 to $89 \mathrm{~km}$ interval on the transect is associated with a city park. Generally the NDVI values are lower within the portion of the transect $(20$ to $90 \mathrm{~km})$ that is indicated as urban within the OLS and classified MSS data. The urban and rural relationships between the NDVI and DMSP data suggest that the urban-rural differences in DMSP data may provide a valuable tool for the assessment of the urban heat-island effect.

It is noteworthy that, compared to the NDVI values in Figure 4, the OLS values seem to better describe neighborhood-scale details that are verifiable with the high resolution classified Landsat MSS data. In an analysis of the transect (Figure 4) data, the OLS-cal values were associated with $10 \%$ more $(28 \%)$ of the variation in the percentage urban values (derived from the classified MSS data) than the NDVI values $(18 \%)$. One explanation of the disparity in resolving urban land cover details between OLS and NDVI (or Tsfc) values is that the latter parameters are more vulnerable to heterogeneity in vegetative cover (or radiating surfaces) within a $1 \mathrm{~km}^{2}$ grid cell. In contrast, the OLS values are from individual light sources that scale to $1 \mathrm{~km}^{2}$ in a cumulative fashion. Thus, at the $1 \mathrm{~km}^{2}$ resolution at which AVHRR and DMSP-OLS data can readily be obtained, the results suggest that the OLS data better characterize the location of urban related features in well-lit cities and metropolitan areas.

NDVI values associated with climatological stations (Table 1) in urban environments typically are lower when compared to the values associated with rural stations. Tsfc values usually display the opposite trend such that the values associated with stations in urban environments are greater compared to those of rural stations. Stations that have large values of the ratio of Tsfc to NDVI (large values of Tsfc and small values of NDVI) would be expected to be located in urban environments. The ratio of Tsfc to NDVI (derived from the AVHRR data), displayed as a function of NDVI for grid cells that are predominantly forested, agricultural, or overwhelmingly urban (derived from the MSS data), are displayed in Figure 5. Only two of the seven climatological stations analyzed were actually located within the borders of the classified Landsat-MSS scene and thereby directly associated with a predominant class (Table 2).

The AVHRR-derived Tsfc and NDVI data available for all seven stations were used to assess the association of the stations with the predominant Landsat-MSS derived classes within the study area. The ratio of Tsfe to NDVI for the
Table 2 Proportion of AVHRR pixels associated with climate stations 282 and 285 that were designated as urban, agricultural or forested with the MSS-based classified image.

\begin{tabular}{crcr}
\hline Station & Urban & Agricultural & Forested \\
282 & $0.4 \%$ & $9.2 \%$ & $62.0 \%$ \\
285 & $29.8 \%$ & $0.4 \%$ & $48.9 \%$ \\
\hline
\end{tabular}

seven climatological stations was compared to the values obtained for those grid cells associated with predominantly urban, agricultural and forested cells within the MSS scene. The ratio of Tsfe to NDVI for station 285 is similar to that associated with the grid cells classified as overwhelmingly urban ( $>80 \%$ urban), while stations 280 and 282 display Tsfc/NDVI values similar to the predominantly forested/ agricultural classes ( $>50 \%$ forested or agricultural). Stations $279,281,283$, and 284 have Tsfe/NDVI values that do not correspond to any one land cover class.

Closer inspection of Table 2 reveals a rather high percentage of forested land cover in the local vicinity of station 285, given its characterization as an urban station. This is not surprising, however, given the intermingling of mature, well-vegetated residential areas immediately adjacent to central Dallas and station 285. Oke (1982) noted that 40$70 \%$ of urban areas in Europe and North America are comprised of varying vegetative surfaces, from lawns to full-grown deciduous trees. In this case, the presence of the latter obscures urban rooftop and street surfaces, which results in an elevated forested classification. It is clear, however, that the $29.8 \%$ urban land coverage dominates the surface energetics in the immediate vicinity of station 285 , as evidenced by relatively low NDVI and high Tsfe values in Table 1.

The OLS-pct values associated with the seven DFW climatic stations are also displayed as a function of NDVI (Figure 6). Generally those stations with large OLS-pct values displayed lower NDVI values. A clear distinction exists between the OLS-pct values of stations 279,281 and 285 , and the other stations. A similar distinction, although not as great, is observed in the OLS-cal data (Table 1). The OLS-pct values suggest that stations 279,281 and 285 might be considered "urban." These three stations were indeed identified as 'urban,' through a manual procedure described in Gallo et al. (1993a).

The OLS data, combined with the NDVI and Tsfe data that describe the surface energetic response to urban land cover, provide a meteorologically sensitive characterization of stations as urban and rural (e.g., Figures 5 and 6). Comparing the urban assessment based on land cover (Figure 5), the relatively large OLS-pct values for stations 279 and 281 in Figure 6 suggest that the OLS data may be particularly useful in discerning urban and rural land covers along the transition zones between classes.

The use of OLS values to characterize stations as urban or rural in the transitional area between urban and rural locations 
could be especially beneficial for future assessments of urbanization-induced temporal discontinuities in temperature observations. Landsberg (1981) pointed out that the largest gradient in urban-rural ambient temperatures occurred along the urban-rural fringe at the periphery of metropolitan areas. Many longterm climate observing stations that are included in historical networks, due in part to their rural settings, will be vulnerable to discontinuous temperature changes due to encroaching urbanization. Planned analyses include the use of AVHRR and DMSP-OLS data to assess the urbanization at stations included in several U.S. and global climatological data sets.

\section{Summary}

The process of urbanization is dynamic. As urban areas expand into regions of varied vegetation, due to culturally diverse land use, assessment of the urban expansion relative to the location of climate observation stations will continue to be critical. This paper demonstrates the value of using multiple sensors in the identification of urban heat islands. The repartitioning of surface energy fluxes due to urban land use change can be implicitly linked to lower values of NDVI and higher values of radiant surface temperature with the AVHRR data. Higher resolution land cover data from classified Landsat MSS data can be used to relate land cover classes to observed changes in NDVI and radiant surface temperature. The DMSPOLS data exploits anthropogenic nighttime light sources as a further tool for the distinction between urban and rural locales. Additionally, the DMSP data may be most applicable in evaluation of urban heat islands in regions that are sparsely vegetated. The information provided by a single sensor, while valuable, can clearly be enhanced by the use of multiple sensors.

\section{Acknowledgments}

Portions of this paper include material from an on-line educational module prepared by Dr. Kevin Gallo, Office of Research and Applications, NOAA, and Tim Owen of the National Climatic Data Center, NOAA. The module is part of the Remote Sensing Core Curriculum (http://www.umbc.edu/rscc), Volume 4, Applications in Remote Sensing. The data included in this analysis were

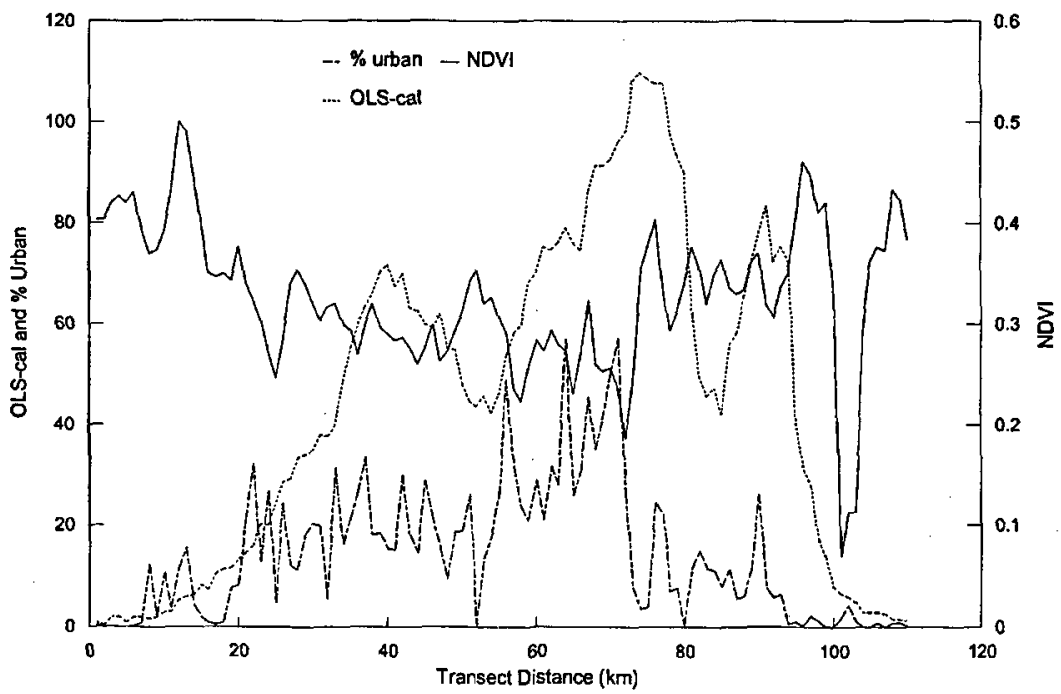

Figure 4 NDVI, DMSP-OLS, and MSS-derived proportion of urban land cover values for a $110 \mathrm{~km}$ transect that includes Dallas and Ft. Worth, TX. The OLS-cal values are scaled such that radiance values $\left(\mathrm{Watts} / \mathrm{cm}^{2} / \mathrm{sr} / \mu \mathrm{m}\right)=$ scaled value $\mathrm{X}\left(1.43 \mathrm{X} 10^{-9}\right)$.

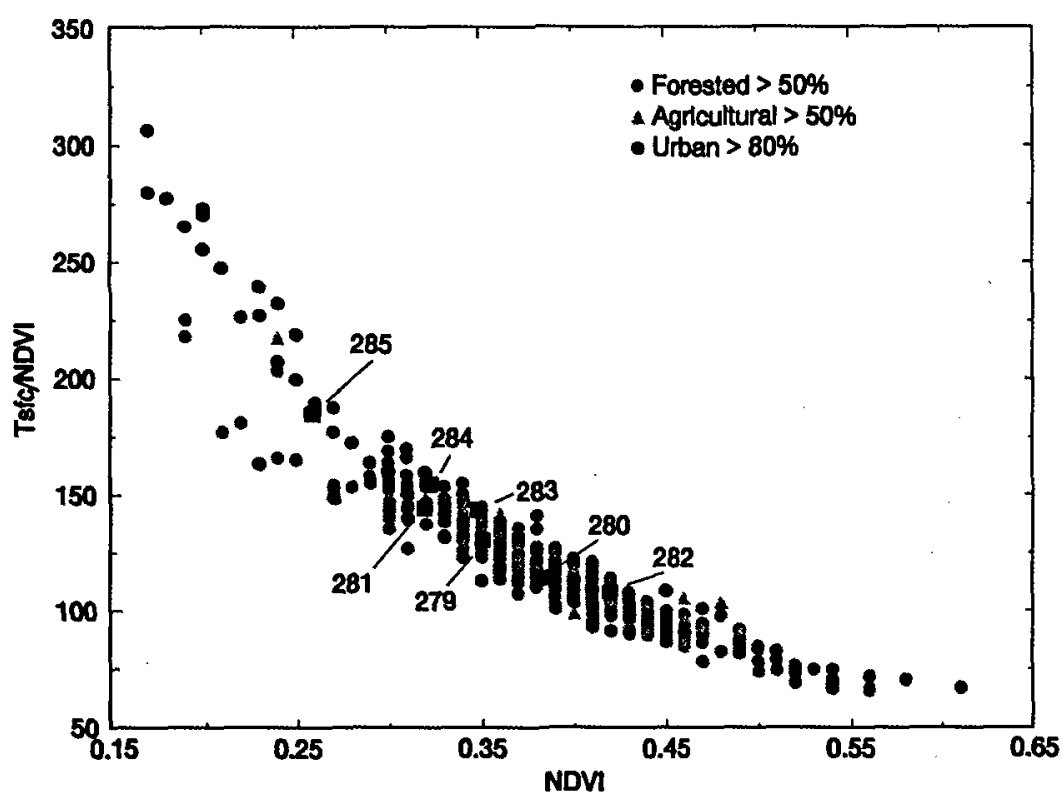

Figure 5 The AVHRR-derived ratio of Tsfe to NDVI displayed as a function of NDVI for grid cells that were classified with the Landsat-MSS data as predominantly agricultural, forested or urban. The Tsfc and NDVI values associated with the seven climatological stations of the DFW region are also identified (blue squares).

provided by NOAA's National Climatic Data Center and National Geophysical Data Center, and the USGS/EROS Data Center. This research was partially funded by NOAA's Office of Global Programs' Climate and Global Change Program and NASA.

\section{References}

Anderson, J.R., E.E. Hardy, J.T. Roach, and R.E. Witmer, 1976. A land use and land cover classification system for use with remote sensor data. U. S. Geological Survey Professional Paper 964. Washington, DC: USGPO, Department of the Interior.

Carlson, T.N., J.K. Dodd, S.G. Benjamin and J.N. Cooper, 1981. Satellite estimation of 


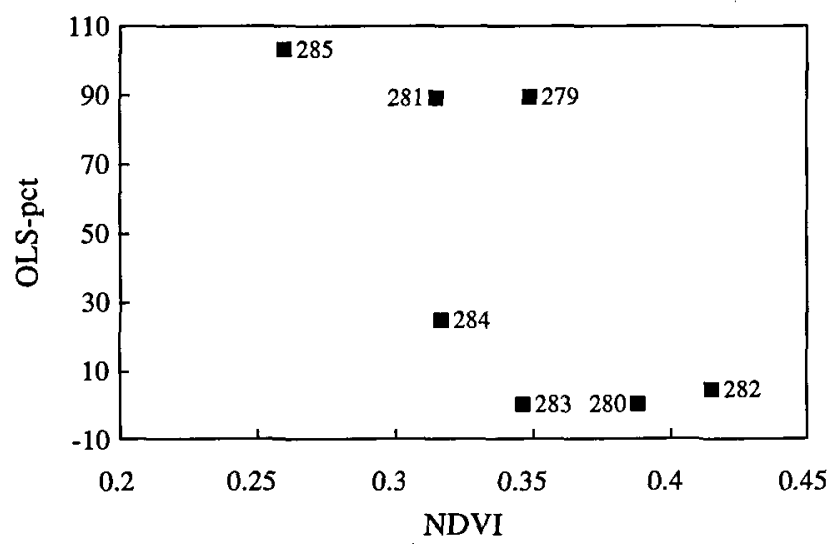

Figure 6 The OLS-pct values associated with the seven climatological stations of the DFW region, displayed as a function of NDVI.

the surface energy balance, moisture availability and thermal inertia. J. Appl. Meteor., 20:67-87.

Changnon, S.A., 1992. Inadvertent weather modification in urban areas: Lessons for global climate change. Bul. Amer. Meteor. Soc., 73:619-627.

Elvidge, C.D. K.E. Baugh, E.A. Kihn, H.W. Kroehl, and E.R. Davis, 1997. Mapping city lights with nighttime data from the DMSP Operational Linescan System. Photogram. Engr. Rem. Sensing, 63:727-734.

Gallo, K.P. and C.S.T. Daughtry, 1987. Differences in vegetation indices for simulated Landsat- 5 MSS and TM, NOAA-9 AVHRR and SPOT-1 sensor systems. Remote Sens. Environ., 23:439-452.

Gallo, K.P., A.L. McNab, T.R. Karl, J.F. Brown, J.J. Hood, and J.D. Tarpley, 1993a. The Use of NOAA AVHRR Data for Assessment of the Urban Heat Island Effect. J. Appl. Meteor., 32:899-908.

Gallo, K.P., A.L. McNab, T.R. Karl, J.F. Brown, J.J. Hood, and J.D. Tarpley, 1993b. The Use of a Vegetation Index for Assessment of the Urban Heat Island Effect. Intl. J. Remote Sens, 14:2223-2230.

Gallo, K.P., J.D. Tarpley, A.L. McNab, and T.R. Karl, 1995. Assessment of urban heat islands: a satellite perspective. Atmospheric Research, $37: 37-43$.
Gallo, K.P., D.R. Easterling and T.C. Peterson, 1996. The influence of land use/land cover on climatological values of the diurnal temperature range. J. Climate, 9:2941-2944.

Goward, S.N., 1981. Thermal Behavior of Urban Landscapes and the Urban Heat Island. Phys. Geog., 2(1):19-33.

Karl, T.R., H.F. Diaz, and G. Kukla, 1988. Urbanization: Its Detection and Effect in the United States Climate Record. J. Climate, 1:10991123 .

Kukla, G., J. Gavin, and T.R. Karl, 1986. Urban Warming. J. Clim. anal Appl. Meterol. 25:1265-1270.

Landsberg, H.E., 1981. The Urban Climate. New York. Academic Press, 275 pp.

Nemani, R.R. and S.W. Running, 1989. Estimation of Regional Surface Resistance to Evapotranspiration from NDVI and Thermal-IR AVHRR Data. J. Appl. Meteor., 28:276-284.

Oke, T.R., 1982. The Energetic Basis of the Urban Heat Island. Quart. J.Royal Meteorol. Soc., 108:1-24.

Oke, T.R., 1987. Boundary Layer Climates, 2nd Edition. London. Methuen \& Co. Ltd., 435 pp.

Price, J.C., 1990. Using Spatial Context in Satellite Data to Infer Regional Scale Evapotranspiration. IEEE Transactions on Geoscience and Remote Sensing, 28(5):940-948.

Roth, M., T.R. Oke and W.J. Emery, 1989. Satellite-Derived Urban Heat Islands From Three Coastal Cities and the Utilization of Such Data in Urban Climatology. Int. J. Remote Sens., 10(11): 16991720.

U.S. Bureau of the Census, 1997. Available online at: (http:// www.census.gov/population/estimates/metro-city/metal95.txt).

USGS, 1990. Land use and land cover digital data from 1:250,000and 1:100,000-scale maps-data users guide 4: Reston, Virginia, U.S. Geological Survey, 33 p.

USGS, 1991. The 1991 Conterminous U.S. AVHRR Biweekly Composites. (Compact Disc), USGS, National Mapping Division, EROS Data Center, Sioux Falls, SD.

USGS, 1997a. Available online at: (http://eosims.cr.usgs.gov:5725/ CAMPAIGN_DOCS/nalc_proj_camp.html).

USGS, 1997b. Land Analysis System, Version 7.0, EROS Data Center, Sioux Falls, SD, 57198. 